\title{
The Status of a Trainee Teacher with Mental-Health Problems: Dilemmas on Inclusion and Exclusion in Higher Education
}

\author{
Lawrence Mundia \\ 4 Simpang 709-18, Jalan Jerudong, Kampung Jerudong \\ Bandar Seri Begawan BG 3122, Brunei Darussalam \\ Tel: 673-893-9465Ｅ-mail: mundia_ljs@yahoo.co.uk
}

\begin{abstract}
The case study reports on a 22-year old female pre-service student teacher pseudo-named P who dropped out of her training program at one of the universities in Brunei due to psychological problems. All the three universities in Brunei with both local and foreign students train teachers. For ethical reasons and information protection laws, the nationality, ethnicity and other identifying information of the student together with the institutional affiliation of the researcher are withheld throughout this study. An informal interview and the MMPI-2 evaluation confirmed that $\mathrm{P}$ had many severe mental-health problems that required a wide range of therapeutic interventions to address. Overall, the study illustrated how gender, interpersonal relationships, and culture interacted to cause distress for P. In addition the results demonstrated the plight of a tertiary student with mental-health problems in a developing country who seemed to be accorded low priority in comparison to peers with other severe disabilities. Moreover, the study also highlighted the importance of psychological assessment in educational counseling and the lack of adequate psychotherapy resources for students with high support-needs in mental-health. Appropriate intervention measures are recommended to reduce the wastage rate among vulnerable students with challenging behaviors in Brunei.
\end{abstract}

Keywords: Psychological assessment, Mental-health, Counseling, Psychotherapy, Trainee teacher

\section{Introduction}

In developed countries, research indicates that there is now an increase in the enrolment of students with severe disabilities in institutions of higher learning due to the sensitization and awareness campaign carried out the last two decades by various forces such as the inclusive education movement and changes to educational policies and legislation (Shute, 2007). Ironically, research also indicates that there is now an increase in mental health problems such as depression among college and university students including all categories of trainee teachers (Benton et al., 2003; Shute, 2007). Previous research on students' mental health problems has focused mainly on depression (Gavin, 2004; Bouteyre et al., 2007); anxiety (Head \& Lindsey, 1983; Eller et al., 2006); and stress (McKean \& Misra, 2000; Burnard et al., 2007a; b). The amount and frequency of anxiety and stress were higher than those for depression (Vaidya \& Mulgaonkar, 2007). In addition depression, anxiety and stress were more prevalent in female students than males (McKean \& Misra, 2000; Eller et al., 2006; Dyrbye et al., 2006). Also, more freshmen were afflicted by these three disorders than sophomores (Capeding, 2002; Pabiton, 2007; Bouteyre et al., 2007). Depression, anxiety and stress appear to be linked to each other but the connections have only been determined by correlation and not experimentally (Andrews \& Wilding, 2004; Edward, 2006). In view of this, it is difficult to establish with certainty if (and how) they cause each other. One possible reason why depression, anxiety and stress and other mental health problems might co-exist may be due to the fact that they share a few common symptoms, causes, and effects (e.g. faulty cognitions or having cognitive distortions). Apart from depression, anxiety, and stress, there are many other mental health problems such as psychoticism and schizophrenia that affect tertiary students. In developing countries these student mental health problems are caused by a host of lifelong factors such as pressure of academic work, poverty, diseases, natural disasters, environmental hazards, war, and unrealistic expectations from parents and teachers (Ovunga et al., 2006). In their recent study, Yates et al. (2008) found that some mental-health problems occur before students enter a college or university. Literature is also abundant on many other mental-health problems (Jenkins et al., 1990; Taylor, 1990; Amchin, 1991; APA, 2000; \& WHO, 2007). In institutions of learning, the mental-health problems are often neglected until the student becomes a danger to the self or others. At that point, the student's undesirable mental-health behaviors begin to indirectly manifest themselves in a number of ways such as the small but steadily growing attrition rates and bizarre dysfunctional behaviors like suicide, stalking, gun-shooting, 
assaulting professors, rape, arson, and gang-behavior. These problems are usually identified with certainty when concerned students are comprehensively assessed using diagnostic observations, clinical interviews, the mental status examination, and psychometric tests. In Brunei Darussalam, the scant research conducted on students' mental- health problems is mainly on stress (Burnard et al., 2007a; b). Much effort and resources in most developing countries, like Brunei, are directed towards helping students with traditional types of disabilities through policies such as inclusive education, special education, and curriculum reforms. Despite these efforts, students in developing countries still largely depend on various alternative sources of help such as parents, friends, and religion to solve their personal problems (Pabiton, 2004; 2007). However, there are signs that the situation is changing slowly in Brunei Darussalam with the increased recognition of psychology, psychiatry, counseling and social work as important mental-health professions. These professions have potential to make meaningful contributions to improving the quality of life for Brunei people.

\subsection{Attitudes to severely disabled learners}

In Brunei, the attitudes of educators towards students with mental health problems in institutions of higher leaning are not yet known due to lack of research. In addition, the number of students with severe challenging behaviors (e.g. behavioral disorders, BD or emotional and behavioral disorders, EBD) and mental-health problems in Brunei tertiary institutions is still small because of the small population and rigorous selection procedures. According to Zarean et al., (2008) emotional disturbance contributes to the onset and persistence of schizophrenia, organic mental disorders, psychosomatic disorders, and personality disorders. Due mainly to the social stigma attached to negative labels pertaining to psychiatric conditions, the few students admitted into Brunei tertiary institutions with BD, EBD or mental-health problems tend to mask their behaviors and are thus invisible. There is also stigma associated with seeking professional psychiatric help (Shute, 2007). In view of these and other reasons, research on students with mental-health problems is still scant in Brunei and the present study was an attempt to narrow this knowledge gap. At the secondary school level, previous research from elsewhere showed that regular school teachers were in general opposed to having disabled learners in their classrooms (Jones et al., 1978; Jamieson, 1984; Knoff, 1985). The more severe or profound the learner's disability, the higher the chance such a learner was likely to be rejected by regular school teachers, non-disabled peers in an inclusive setting, and parents of non-disabled students (Heward, 1996). Among students with partial or mild disabilities who were includable in ordinary schools, regular teachers preferred most those who had learning difficulties and liked least learners with mental and behavioral disorders (William \& Algozzine, 1979; Vandivier \& Vandivier, 1981). This might be partly due to the fact that students with mental and behavioral disorders pose the biggest challenge to teaching and assessment. In addition many teachers may not know how to handle learners with mental-health problems. A major concern that is often raised when a student with high support needs is included in a mainstream classroom is the fear that his or her presence and participation might detract and retard the academic progress of the non-disabled peers (Hunt \& Goetz, 1997). Moreover, regular teachers often think that the placement of disabled learners in ordinary classrooms might influence teaching effectiveness (Myles \& Simpson, 1989). These negative attitudes are gradually becoming positive with the wide availability of sensitization programs as well as preserve and in-service courses in special education. Hunt and Goetz (1997) reviewed 19 studies of inclusive educational programs, practices, and outcomes for students with severe disabilities. Their meta-analysis revealed that learners with severe disabilities were includable in ordinary schools, and that they could achieve positive academic and learning outcomes, contrary to the unfounded fears or concerns held by many stakeholders. The two researchers found that inclusion of severely disabled learners into regular schools was more effective and beneficial where and when:

- “ " parental involvement was made an essential component of inclusion;

- the school / classroom environment fostered acceptance, social interactions, and friendships;

- $\quad$ teaching and learning were a collaborative effort involving the major stakeholders; and

- $\quad$ appropriate curricula adaptations and accommodations were made" (Hunt \& Goetz, 1997: 25-26).

Universities in Brunei Darussalam admit into their academic programs students with different categories of disability. One student with profound visual impairment (total blindness) graduated a few years ago at P's institution. Another student with severe physical disabilities was due to graduate at the same institution $\mathrm{P}$ was attending. Students with disabilities rarely drop out at P's university because of the support they receive from and accommodations made to them by the University. However, the student with mental-health problems discussed in this Study broke the trend and challenged the University when she dropped out of her degree training program. The present Study seeks to answer the question: what was the difference between this mentally disturbed student and the other students with similarly severe disabilities who never dropped out? Surely there 
were factors that forced this unique student to discontinue her training and such self-exclusion was in itself educational wastage that needs to be probed, prevented, or addressed. Since the inclusion and later exclusion of the student in the present study involved only one person, critics and skeptics may say that they see no links or connections between the plight or fate of one student and the broader issues of teacher education and regular education in tertiary institutions. The truth is that the philosophies of the Education for All (EFA) and inclusive education movements require that problems of all learners be addressed. This includes addressing the problems of single students with rare or unique behaviors on college and university campuses.

\subsection{Psychology and psychologists in Brunei Darussalam}

Psychology in Brunei has not yet reached the level of Japan (see Sato, 2005), India (Jain, 2005), and Pakistan (Suhail, 2004) whose universities offer masters and doctoral degrees in this discipline. Psychology is also less used as a mental-health profession in Brunei than in other Asia-Pacific countries, such as Australia and New Zealand with well developed counseling and psychotherapy infrastructure and resources as part of their overall health-care facilities. However, mental-health well-being in Brunei is far ahead than in other small countries in the Pacific-Southeast Asia region, such as Vanuatu (see Forster, 2005), Samoa, Kilibati, Tuvalu, and Nauru. Most psychological services in Brunei are dispensed in the field of education. Since 1998, the Country has had special schools called Centers that serve learners with high support-needs and an inclusive education system that integrates students with mild and moderate disabilities into mainstream schools (Ministry of Education, 1997; 1998). Implementation of the education program for gifted and talented students started in 2008 (Ministry of Education, 2008). In addition, the Ministry of Education also has a Special Education Unit (Wong, 2005) and a Counseling and Career Guidance Section (Yahya, 2005). The Government has, through the Ministry of Education and the University of Brunei Darussalam (UBD), sponsored two international conferences on special education in 1997 and 2005, and one international conference on counseling in 1998. Recently, the Government launched a Counseling Unit on 14 April 2005 within the Institute for Public Administration (IPA) for use by civil servants and also created the "Brunei Darussalam Journal of Special Education" on 6 June 2005 for researchers to publish the outcome of their investigations. The Counseling Unit at IPA deals mainly with occupational, financial, and family-related problems while the Bureau for Narcotics deals with drug and forensic problems. The University of Brunei Darussalam (UBD) offers an MEd in Special Education. According to the policy of the Ministry of Education, all trainee-teachers (pre-service and in-service) are required to take courses in inclusive education, educational psychology as well as guidance and counseling. Upon the completion of their training, some teachers in secondary schools are appointed as guidance counselors. The Institute of Medicine at UBD also offers courses in applied psychology (clinical and counseling) to medical students. In addition, each university has a Counseling Unit used mainly by students. Furthermore, the major hospitals in the country have Psychiatric Units that attend to patients with mental-health problems. These developments suggest that the value of Psychology as a human health-care profession in Brunei is increasing, and that it might grow bigger in future. Overall, Brunei still lacks adequate counseling and psychotherapy resources in private-practice, hospitals, and industry at present. More attention, effort, and resources need to be directed to these areas of health-psychology in this country. Psychological assessment or testing is considered a dilemmatic issue in counseling and psychotherapy because there are many arguments both for and against it. According to Corey (1991) counselors who favor the use of diagnosis in therapy generally argue that it enables the practitioner to acquire enough knowledge about the client's past and current behavior to develop an appropriate plan of treatment. On the other hand critics and skeptics of psychological testing such as Yalom (2001) see diagnosis as unnecessary or harmful because of the negative labels used.

\subsection{Objectives of the study}

Using the mental-health problems a student had at one university in Brunei, the Study probed the three broad research questions listed below. Through these questions, the Study addressed the problems surrounding the inclusion and exclusion of students with mental-health problems in tertiary institutions of learning within a developing country context.

- What was the problem?

- Why did the problem persist? and

- $\quad$ How could the problem be resolved?

\section{Investigative method}

The Case-study research method was adopted in investigating and probing the problem. The rationale and justification for using this approach was based on three reasons. First, the Study was exploratory and intended to 
find out the possible presenting problems of the student in the Case-study. Second, only one student was involved in the Case study. Third, the overall goal of the research was to sensitize the public (to the likelihood) that there could be many other students in Brunei institutions of higher learning with similar mental-health problems. Such students need the help of mental-health professionals to prevent them from dropping-out and contributing to wastage statistics in education.

\subsection{The participant}

The person discussed in this case-study is pseudo-named $\mathrm{P}$ throughout the text. $\mathrm{P}$ was a 22-year old female pre-service student-teacher at one of the three universities in Brunei Darussalam who had intense personal problems. Despite her problems, $\mathrm{P}$ was an above-average student in academic work. She was a polite, well-behaved, and a pleasant student to work with. During the second year of her 4-year program, P confidentially and voluntarily reported to the Researcher (who was one of her lecturers) that she felt overly-nervous whenever she was required to participate in course tutorial discussions and teaching-practice (peer-teaching and micro-teaching). Most courses at her institution required students to participate actively during the tutorials. She requested to talk about the issue with the Researcher. The Researcher immediately arranged (within the same week) a one 30-minute informal interview to privately discuss her problems in a safe office environment. P cooperated and attended the interview. During the interview, P verbally indicated that she was always afraid of talking when in a group of people including the peers. The University administration was aware of P's problems and referred P to the University's Counseling Unit for help. After a while, the Counseling Unit, in turn, referred $\mathrm{P}$ to the Psychiatric Unit at one of the hospitals in the country. P was not admitted in the hospital, and as an out-patient she continued attending her classes at the University. Being a sponsored student, her scholarship did not permit her to change to a study program that was less threatening to social interaction. As the severity of her problems increased, the situation became unbearable and P eventually dropped out of the program in the middle of the second year.

\subsection{Data collection instrument}

Prior to quitting the University, P voluntarily agreed to participate in a study along with other trainee-teachers in which the current Researcher was investigating the social desirability orientations of the student-teachers. Participants in this Study were requested to complete the entire MMPI- 2 scale. In addition, the participants also agreed (as part of the informed consent) that the Researcher could use the obtained data for other psychological inquiries. On the basis of this understanding, data were obtained indirectly on P for this Study and her whole protocol was analyzed further to shed light on her presenting problems. The MMPI-2 (Hathaway \& McKinley, 1989 ) is a 567-item psychometric personality-test consisting of 3 validity scales, 10 clinical scales, and several supplemental scales. The Test is normally administered individually on referred cases in clinical settings. At the time of conducting and writing this Study, there were no studies on Brunei tertiary students based on the MMPI-2. In view of this, the Test's reliability and validity with Brunei student populations were unknown. However, the Instrument is well-researched and well-established with good reliability and validity in many clinical contexts. In addition to completing the MMPI-2, P also had a 30-minute informal interview with the Researcher in which she discussed her problems. P voluntarily requested for this interview with the Researcher.

\subsection{Instrument administration procedures}

Before administering the Instrument, the participants were told verbally about the ethical conditions and requirements for their involvement in the Study. This discussion focused on seven ethical issues (voluntary participation, privacy, anonymity, confidentiality, protection from physical and psychological harm, debriefing, and informed consent). In addition, the participants also agreed (as part of verbal informed consent) that the Researcher could use the obtained data for other psychological inquiries. On the basis of this understanding, data were obtained indirectly on P for the present Study. The meanings of difficult words (sentences or phrases) involving six items (Items 17, 65, 116, 388, 426, and 444) were verbally explained to the participants before the Instrument was administered. However, the Instrument is written in basic English and Brunei University students completed it without any major problems. In view of this, it was deemed not necessary (by the Researcher) to translate the Instrument into Bahasa Melayu (Brunei's natural and official language). Furthermore, students at UBD take courses in English language and have participated in numerous research-studies that required them to complete self-report scales or questionnaires in English. Although the Instrument may be completed in about 30 minutes by people who speak English as a native or first language, the Brunei student sample took more than one hour to have it done. A few students needed an hour and half to complete it. As usual and as expected, some questions were not answered by a small number of participants, and this resulted in few protocols not being usable due to many missing values. Fortunately, P responded appropriately to all the items in the scale. The 
data-collection procedure complied with the ethical requirements of the University and the Government of Brunei on the use human participants in research. The Study also met the requirements of the Helsinki Declaration on the use of human subjects in research.

\subsection{Data analysis}

$\mathrm{P}$ answered all the items appropriately on the MMPI-2. A battery of validity and clinical scales plus selected supplemental scales were scored (according to instructions in the technical manual) on P's protocol. Both raw and standardized $\mathrm{T}$ scores (with K-correction where necessary) were obtained. Data from the interview was analyzed qualitatively using content-analysis and constant-comparison procedures (Lincoln \& Guba, 1985; Patton, 1990).

\section{Results}

The findings of the Study are presented below under four separate sections / subheadings (informal interview; validity scales; clinical scales; and supplemental scales). These findings address the first research question: what was the problem? It turned out that $\mathrm{P}$ had numerous severe and multifaceted problems. It should be noted at the outset that the obtained data were interpreted cautiously due to the limitations of the Study (collecting data using only one interview and one inventory) noted below. A complex case like P, needed to be comprehensively evaluated using a variety of procedures in order to get a clearer and better picture of her problems. However, prior to this small-scale assessment, the Researcher had practically no idea about the sort of problems $P$ had and how they could be tackled.

\subsection{Findings from the informal interview}

Throughout the interview, the Researcher observed that $\mathrm{P}$ was calm and remained in a stable mental-state. This might be due to the fact P used to come to the Researcher's office occasionally to get course hand-outs. The interview environment was therefore familiar and friendly and may have had good ecological validity. During the interview, $\mathrm{P}$ made several references to her father, who she claimed was too domineering and whose personality she described as narcissist. P further alleged that she was over-protected by her father who never allowed her to socialize with peers. She accused her father of being unfair to her by allowing her brothers freedom to interact with peers. From what transpired in the interview probes and the father's assumed gender-bias, it seemed that P did not have a cordial relationship with her father. Because P's parents were not living in Brunei at the time of collecting the data, a joint-interview with the parents could not be conducted to obtain further information on this case. One initial interview was therefore not enough to have a prolonged engagement with P and observe her adequately. Rather than deal with P's complex problems, the University found it easier to let her drop out.

\subsection{Findings from the validity scales}

It can be noted from Table 1 that P's standard scores on the $\mathrm{L}$ and $\mathrm{K}$ validity scales were within the normal range. However, her score on the F scale was elevated far above the average $(T=50)$ and this raises concerns about interpreting her profile correctly. A high score on F may be interpreted in many ways. People who score high on the F scale tend to endorse 'true' and 'false' responses, generally marked by less than $5 \%$ normal adults ( hence the name infrequency scale). This might be due to random-marking of responses which may invalidate the profile. Alternatively, a high F-score may be an indication of a high degree of mental-confusion or psychopathology in the respondent. The test-administrator has to observe the client carefully. An inflated F score might also mean that the respondent made a deliberate attempt to fake bad, magnify, or exaggerate psychological symptoms. Of these three competing interpretations, a high F score in this Study probably provided hints for greater psychiatric disturbance in the student. This is because of the high trust $\mathrm{P}$ had in the Researcher and the good professional / helping relationship that existed between P and the Researcher.

$<$ Insert Table 1 Here $>$

\subsection{Findings from the clinical scales}

On the clinical scales, Table 1 shows that 8 of P's 10 scores fell in the clinical range $(\mathrm{T}>65)$. $\mathrm{P}$ obtained a personality profile code of $64 / 23$ on the basic (clinical) scales. Her first and second highest scores were on scales 6 and 4 respectively. The third and fourth highest scores were obtained on scales 2 and 3 respectively. P's profile-pattern provided several clues regarding her presenting problems. The profile suggested that she had severe mental-health problems in the areas assessed by scales 6, 4, 2, and 3. Her psychological problems in areas measured by scales 8,1 , and 10 appear to have been moderate. In addition, $\mathrm{P}$ also had two other mild psychological problems, illustrated by above-average scores on scales 7 and 9 . 
$<$ Insert Table 2 Here $>$

\subsection{Findings from the supplemental scales}

P's $\mathrm{T}$ scores were also in the clinical range on 8 of the 10 supplemental scales presented below in Table 2 . Evidence from this table indicates that $\mathrm{P}$ had severe family problems and familial discord. This was supported earlier by her revelation above during the informal interview. It can also be observed from Table 2 that $\mathrm{P}$ was highly anxious and scored high on related attributes such as social avoidance, social discomfort, alienation, and self-esteem. In Table 1 she scored high $(\mathrm{T}=70)$ on the social introversion scale. These additional scales provide ample hints as to why $\mathrm{P}$ was possibly nervous to speak to her peers in formal learning settings at the University. Not surprisingly, P scored high on the post-traumatic stress disorder scale (PK). This was probably due to the fact that she was besieged by too many different severe problems that eventually forced her to leave the Program. The combined effect of all the many and diverse presenting problems might have been catastrophic and traumatic.

\section{Discussion}

This section of the Study addresses the second and third research questions of the investigation, namely: why did the problem persist? and how could the problem be resolved? The implications of the findings of the Study to the local Brunei and international community on the well-being of students with mental-health problems in high institutions of learning, are described in the relevant sections below. Educators, mental-health practitioners, and parents in other developing-nations may be interested to know that cases of university students like $\mathrm{P}$ also exist in other developing-countries. Finding durable and meaningful solutions to complex problems of this nature often requires international cooperation.

\subsection{Why did the problem persist?}

There are probably many reasons and theories to explain why P's problems recurred. Only four of these plausible contributing factors are discussed here. First, the results of the study presented above indicated that $P$ had numerous and different psychological problems. The process of identifying all these problems properly using a variety of suitable methods required considerable time and effort. Second, most of P's problems were severe. In view of this, it may be assumed that effective treatment of the problems needed both a long-term intervention plan and a number of mental-health specialists experienced in treating various concerns. Long treatments offered by teams often have many complications. Third, although P was (as explained above) referred to a Counseling Unit (CU) at her University, the effect of the CU on P's problems is unknown because of the privacy and confidentiality laws and other ethical considerations. Whatever happened at this stage, P's problems appear not to have been resolved satisfactorily by the CU. This observation seems to be supported by the fact that the CU, in turn, also ended up referring P to a Psychiatric Unit (PU) at one of the hospitals. Again, the type and effect of the intervention and interaction between $\mathrm{P}$ and the PU cannot be known because of the information protection laws. Fourth, despite visiting the PU as an outpatient, P's problems at that time were on the increase rather than decreasing, and eventually she left the University. Her exit gave rise to speculation that the intervention she received from the PU might not have been adequate.

\subsection{How could the problem be resolved?}

From the Researcher's understanding of the case under study, it seems there were three actions that needed to be undertaken to help resolve P's problems. To identify and confirm her major concerns, $\mathrm{P}$ needed to be comprehensively assessed in a variety of ways including obtaining her personal history, family background, and medical records as well as using diagnostic observations, clinical interviews, objective tests, and a mental status examination in ecologically ideal environments. The Diagnostic and Statistical Manual, DSM-IV (APA, 2000) and the International Classification of Diseases, ICD-10 (WHO, 2007) may have been used to help classify P's problems. Some of P's scores on the MMPI-2 clinical scales, such as paranoia, psychopathy, hysteria, schizophrenia, hypochondrias, psychasthenia, and hypomania, needed further psychiatric evaluations. The basic descriptions for the high and low scorers on the MMPI-2 scales would be familiar to most readers from the literature (Jenkins et al., 1990) and the technical manual (Hathaway \& McKinley, 1989). These assessments might have assisted in developing and guiding informed therapeutic decisions and choices. The next stage would have involved the construction of a long-term treatment plan based largely on the assessment outcomes. Such a plan needed to carefully take into account the nature and extent of P's multifaceted problems. Some examples of the issues that needed to be included in the intervention regime are presented in Table 3. Once a realistic intervention plan was in place, the final logical action would have required its implementation.

$<$ Insert Table 3 Here $>$ 
With so many different problems, treating $\mathrm{P}$ would have been a daunting and challenging task. No single mental health professional could treat all of P's problems. Similarly, no single therapy could address all of P's concerns. As suggested in Table 3, P's problems needed to be grouped into categories of related difficulties. The integrated treatment could then be conducted in phases (each stage targeting one cluster of inter-related behaviors). For instance, the first phase might have addressed the family-based problems using the professionals and techniques outlined in Table 3. One of the most useful techniques in family counseling is rational emotive therapy, RET (Jones, 1969; Ellis, 1973). This strategy examines peoples' dysfunctional thoughts, feelings and beliefs (TFBs) that are irrational and unrealistic in a given context, such as the family, school, or work place. Phase two may have dealt with issues of depression, anxiety and stress that mainly resulted from P's interactions with people in the home and school environments. These problems may be relieved by the use of relaxation as a coping-strategy. They also seem to respond well to cognitive-behavioral therapies, CBT (Beck, 1967) that look into people's faulty thinking such as having cognitive distortions and dissonance; absolutistic or perfectionist thinking; and automatic thoughts. The social phobias that appear to have occurred mostly in the school and work contexts might have been the focus of the third phase of the intervention plan. Literature suggests that systematic desensitization (SD) and social skills training (SST) may be effective in treating most social phobias (Fogiel, 1989; Leary, 1981). The psychiatric conditions such as schizophrenia and hypomania could have been addressed in a hospital setting by psychotherapy or drug therapy (DT) or a combination of these two depending on the nature and severity of the problem (see Jenkins et al., 1990). Based on the outcomes from diagnostic observations, clinical interviews, and psychometric tests, additional groups of related problems could be included in the treatment plan. In this way, $\mathrm{P}$ was going to have many referrals (an experience that would be potentially confusing and frustrating if not planned and executed well). The whole treatment plan would have required a lot of cooperation from all those involved in its implementation. Furthermore, all of P's session therapeutic strategies, phase terminations, phase referrals, and phase follow-ups to prevent any relapse, needed long and careful consideration during planning. Her progress also required constant monitoring and evaluation. On the basis of the present limited available information, it appears that $\mathrm{P}$ needed a long-term intervention rather than brief therapy.

\subsection{Implications of findings on students' welfare}

The case of $\mathrm{P}$ brings to the forefront the need to attend to the problems of tertiary students with mental-health problems. At the moment, the needs of such students appear to be accorded a low status and priority compared to the needs of students with traditional disabilities. At primary and secondary school levels, literature on special education indicates that students with mental retardation or mental health problems are thought by regular teachers to be the most difficult to teach (Heward, 1996) and the least preferred (William \& Algozzine, 1979; Vandivier \& Vandivier, 1981). In general, most students may not know that they have or are living with a mental-health problem that needs to be addressed. To bring awareness to such issues, sensitization-workshops could be conducted by psychologists and counselors within each University for students. Students who suspect that they might have a psychological or psychiatric problem should be encouraged by the University to undergo voluntary comprehensive assessment by specialists in mental-health. Sometimes, lay-observations by lecturers, parents, and peers may initially be helpful in identifying students at-risk of developing psychological / psychiatric problems. In some cases, mental-health professionals would have an ethical and legal obligation to warn if the behavior of the person concerned is harmful or injurious to the self and others. In the case of $\mathrm{P}$, her situation was dilemmatic in that her behavior was not dangerous to other people, and yet it was destructive enough to the self to the extent it hindered and prevented her from continuing with her studies (self-actualizing). P's problem appeared to have posed a choice-dilemma to the University: to help her or to let her go. Eventually, P left the University. Morally and ethically, it would have been in the best interests of $P$ if the University had, in consultation with the parents, continued looking for alternative ways to help her. The University is supposed to assist and support students in all possible ways to promote good mental-health. For instance, $\mathrm{P}$ needed to be encouraged to seek further professional help within and outside Brunei, if necessary. Such advice was not going to be an infringement of P's rights to decision-and-choice making but rather seen to be in her best interests (as ignoring her difficulties would be a form of negligence and uncaring attitude). Once the condition is confirmed, the concerned student(s) should be encouraged by parents and University authorities to consider going into voluntary counseling or psychotherapy to address the problem. If the problem is severe, then the student(s) should be given enough information about the possible advantages of seeing a psychiatrist to benefit from both psychotherapy and drug therapy. P's main and immediate problem as a student-teacher was anxiety which disabled her from performing peer-teaching, micro-teaching and teaching-practice (all essential aspects of teacher-training). Anxiety could be treated as indicated in the suggested intervention schedule, presented in Table 3 above. However, for the intervention to be successful the University needed to have well-trained and 
experienced mental-health practitioners (counselors and psychotherapists). These ideas could be incorporated into the University-wide drop-out prevention policy. In terms of the current data-protection laws, information on $P$ accumulated by the University and the Hospital could technically only be released to a third party under three circumstances: (1) when the client or patient is referred to another mental-health specialist or facility; (2) when subpoenaed by a court of law; and (3) when the client is dangerous to the self and others and the duty to warn becomes apparent. The present study proposes that custodians of the data on P should also (in strict confidence) make available the information to counselors and psychotherapists for research purposes to further help unlock P's problems and the possible solutions. Research-based solutions would help the educational institutions to deal more effectively with cases of this nature in future. Unless something is done along these suggestions, students with mental-health problems may continue to drop out of the schools thereby contributing to wastage statistics in Brunei tertiary education system. The wastage problem might grow bigger with the increase in population and student numbers. Brunei Darussalam cannot afford to do away with such essential human resources. Early identification of problems and early intervention are the key to prevention of major psychological and psychiatric conditions. In their study, Yates et al. (2008) recommended that pastoral care mechanisms in higher education institutions need to be enhanced to identify and support potentially vulnerable students.

\subsection{Overall implications from the findings}

The findings from this Study demonstrated the need for parents, institutions of higher-learning, and mental-health specialists to work collaboratively in assisting students with mental-health problems, such as P. The results also illustrated the lack of adequate counseling and psychotherapy resources at the University and possibly other tertiary institutions of learning in Brunei for students with mental-health problems. The required programs and resources may include sensitization programs, voluntary assessment or screening, self-referral, and appropriate therapists. The students' mental-health problems need to be addressed to prevent wastage. The fact that students with high support-needs in other disability areas have not dropped out from P's University, suggests that learners with mental-health problems might be accorded a low status or priority, and that they may not be receiving adequate attention and support accorded to their counterparts. In addition, the extent to which factors such as gender, inter-personal relationships, and culture contributed to the exclusion of $\mathrm{P}$ from training also needs to be carefully examined. For example, findings from the informal interview indicated that P's home environment was more favorable to male, than female, children in the family.

\section{Conclusion}

The Study discussed the mental-health problems student P had while at the University. Although the Study used one case for illustrative purposes, it was argued that there might be many other tertiary students with such problems in Brunei and elsewhere. The best way these students could be identified, is through voluntary psychological assessment and self-referral for counseling and psychotherapy. The plight of students with mental-health problems was high-lighted. Overall, the findings (of the Study) have important educational implications to the local and international community regarding the inclusion and exclusion of students with mental-health problems in tertiary institutions of learning. Further research (both qualitative and quantitative) on students with mental-health problems is needed in Brunei, to gain more understanding of the problem. The present Study is a contribution to the generation of such information.

\section{Limitations of the Study}

This Study was informed by a few limitations. Quantitative evidence for the reliability and validity of the MMPI-2 subscales used in data-collection was not obtained prior to conducting the Study. In practice however, the MMPI-2 is normally administered to individual clients in counseling or psychotherapy settings. In the present Study, the criterion-related validity was particularly needed to demonstrate the MMPI-2's theoretical relationship with similar scales such as the Symptoms Checklist, SCL-90-R (Derogatis, 1977) in the Brunei context. As a case- study, the results of the research did not show cause-and-effect relationships of the variables investigated. In addition, the findings had low external validity and could not be generalized to other students at UBD. Furthermore, the concerned student was not interviewed after administering a psychological instrument/test. A post-administration briefing meeting with the student was needed to provide feed-back information to the Participant and probe her performance on the instrument/test. Qualitative information would have helped reveal the extent to which the Student's responses in the interview matched, differed from, or added to the data gathered by the MMPI-2 survey instrument. In this way, the second qualitative component would have enhanced the findings of the Study. These and other limitations did not, however, adversely affect the results of the Study. 


\section{References}

Amchin, J. (1991). Psychiatric Diagnosis: A biopsychosocial approach using DSM-III-R. Washington, DC: American Psychiatric Press.

American Psychiatric Association, APA. (2000). Diagnostic and statistical manual of mental disorders, $4^{\text {th }}$ edition text revision, DSM-IV-TR. Washington, DC: American Psychiatric Association.

Andrews, B., \& Wilding, J. M. (2004). The relationship of depression and anxiety to life-stress and achievement in students. British Journal of Psychology, 95(4), 509-521.

Beck, A. T. (1967). Depression: Causes and treatment. Philadelphia: University of Pennsylvania.

Bouteyre, E., Maurel, M., \& Bernand, J-L. (2007). Daily hassles and depressive symptoms among first year psychology students in France: The role of coping and social support. Stress and Health, 23, 93-99.

Burnard, P., Bennett, K., Edward, D., Rahim, T. A., Tothova, V., Baldacchino, D., Bara, P., \& Mytevelli, J. (2007a). A comparative longitudinal study of stress in student nurses in five countries: Albania, Brunei, the Czech Republic, Malta and Wales. Nurse Education Today, 6 June 2007.

Burnard, P., Rahim, T. A., Hayes, D., \& Edwards, D. (2007b). A descriptive study of Bruneian student nurses' perceptions of stress. Nurse Education Today, 27(7), 808-818.

Capeding, L. J. (2002). Counselling U. P. Manila freshman students: Issues, concerns, expectations, outcomes and program. The PGCA Guidance Journal, 31 (1), 23-30.

Corey, G. (1991). Theory and practice of counseling and psychotherapy. Pacific Grove, CA: Brooks/Cole.

Derogatis, L. R. (1977). The SCL-90-R manual I: Scoring, administration and procedures for the SCL-90-R. Baltimore, MD: Clinical Psychometric Research.

Dyrbye, L. N., Thomas, M. R., \& Shanafelt, T. D. (2006). Systematic review of depression, anxiety and other indicators of psychological distress among U.S. and Canadian medical students. Acad Med, 81(4), 354-373.

Edward, F. (2006). The truth about stress. [Online] Available: http://www.stress-anxiety-depression.org/print/stress/truth-about-stress.html (November 20, 2007).

Eller, T., Aluoja, A., Vasar, V., \& Veldi, M. (2006). Symptoms of anxiety and depression in Estonian medical students with sleep problems. Depression Anxiety. 23 (4), 250-256.

Ellis, A. (1973). Humanistic psychotherapy: the rational emotive approach. New York: Julian Press.

Fogiel, M. (1989). The psychology problem solver. Piscataway, NJ: Research and Education Association.

Forster, P. (2005). Psychology in Vanuatu. The Psychologist, 18 (5), 288-289.

Gavin, K. (2004). Public document released at the depression on college campuses conference organized by the University of Michigan Health System, 9-10 March.

Hathaway, S. R., \& McKinley, J. C. (1989). Minnesota multiphasic personality inventory - 2 (MMPI-2). Minneapolis, MN: University of Minnesota Press.

Head, L. G., \& Lindsey, J. D. (1983). Anxiety and the university student: A brief review of the professional literature. College Student Journal, 17(2), 176-182.

Heward, W. L. (1996). Exceptional children: An introduction to special education.Englewood Cliffs, CA: Merrill / Prentice Hall.

Heward, W. L. (1996). Exceptional children: An introduction to special education. Englewood Cliffs, CA: Merill / Prentice Hall.

Hunt, P., \& Goetz, L. (1997). Research on inclusive education programs, practices and outcomes for students with severe disabilities. Journal of Special Education, 31 (1), 3-29.

Jain, A. K. (2005). Psychology in India. The Psychologist, 18 (4), 206-208.

Jamieson, J. D. (1984). Attitudes of educators toward the handicapped. In R. L. Jones (Ed.), Attitudes and attitude change in special education: Theory and practice (pp. 206-222). Reston, VA: Council for Exceptional Children.

Jenkins, S. C., Gibbs, T. P., \& Szymanski, S. R. (1990). A pocket reference for psychiatrists. Washington, DC: American Psychiatric Press. 
Jones, R. G. (1969). A factored measure of Ellis' irrational belief system with personality and maladjustment correlates. Doctoral dissertation, Texas Technological College. (University Micro-film, No. 69-6443).

Jones, R. L., Gottlieb, J., Guskin, S., \& Yoshida, R. K. (1978). Evaluating mainstreaming programs: Models, caveats, considerations, and guidelines. Exceptional Children, 44: 588-601.

Knoff, H. M. (1985). Attitudes towards mainstreaming: A status report and comparison of regular and special educators in New York and Massachusetts. Psychology in the schools, 23: 411-418.

Leary, M. R. (1991). Social anxiety, shyness and related constructs. In J. P. Robinson, P. R. Shaver \& L. S. Wrightsman (Eds.), Measures of personality and social psychological attitudes. (pp. 161-194). San Diego, CA: Academic Press.

McKean, M., \& Misra, R. (2000). College students' academic stress and its relation to their anxiety, time management and leisure satisfaction. American Journal of Health Studies, Winter Issue, 1-14.

Ministry of Education. (1997). Special education policy guidelines. Bandar Seri Begawan: Special Education Unit.

Ministry of Education. (1998). Handbook on Special Education for Primary School Headmasters: Outline of Policies and Procedures Dealing with Special Education. Bandar Seri Begawan: Unit Pendidikan Khas.

Ministry of Education. (2008). ADHOC Committee on Education Programme for GiftedStudents. Bandar Seri Begawan: Unit Pendidikan Khas.

Myles. B. S., \& Simpson, R. L. (1989). Regular educators' modification preferences for mainstreaming mildly handicapped children. Journal of special Education, 22 (4): 479-491.

Ovunga, E., Boardman, J., \& Wasserman, D. (2006). Undergraduate student mental health at Makerere University, Uganda. World Psychiatry, 5(1), 51-52.

Pabiton, C. P. (2004). Concerns, issues and coping strategies of international students inselected private universities in the Philippines. Philippines Journal of Counseling Centres, 6, 22-31.

Pabiton, C. P. (2007). Problems and coping strategies of university students: Implication for counseling centres. Philippines Journal of Counseling Centres. 6, 78-95.

Sato, T. \& Fumino, Y. (2005). Psychology in Japan. The Psychologist, 18 (3), 156-157.

Shute, N. (2007). Mental health problems common on college campuses. [Online] http:/health.usnews.com/usnews/health/articles/070417/17vatech.mental health.htm (December 10, 2009).

Suhail, K. (2004). Psychology in Pakistan. The Psychologist, 17 (11), 632-634.

Taylor, R. L. (1990). Distinguishing psychological from organic disorders: Screening psychological masquerade. New York: Springer Publishing Company.

Vaidya, P. M., \& Mulgaonkar, K. P. (2007). Prevalence of depression, anxiety and Stress in undegraduate medical students and its correlation with their academic performance. Indian Journal of Occupational Therapy, 39 (1), 7-10.

Vandivier, P. L., \& Vandivier, S. C. (1981). Teacher attitudes toward mainstreaming exceptional students. Journal for Special Educators, 7: 381-388.

Williams, R. J., \& Algozzine, B. (1979). Teachers' attitudes toward mainstreaming. The Elementary School Journal, 80 (2), 63-67.

Wong, J. (2005). Special education in Brunei Darussalam. Brunei Darussalam Journal of Special Education, 2, $1-15$.

World Health Organisation, WHO. (2007). International classification of diseases $10^{\text {th }}$ edition test revision clinical modification, ICD-10-CM. Geneva: United Nations.

Yahya, R. A. (2005). Counselling camp at Rimba secondary school. Borneo Bulletin, Thursday 9 June 2005, page 6 .

Yalom, I. D. (2001). The gift of therapy: reflections on being a therapist. London: Piatkus.

Yates, J., James, D., \& Aston, I. (2008). Pre-existing mental health problems in medical students: a retrospective survey. Medical Teacher, 30 (3), 319-321. 
Zarean, M., Assadollahpour, A., Bahadori, Z., Ayatmehr, F., Bakhshipour, A., \& Dadkhah, A. (2008). Emotional intelligence and psychopathology in Iranian university students. Middle East Journal of Family Medicine, 6 (3), 12-17.

Table 1. Assessment Outcomes from MMPI-2 Validity and Clinical Scales

\begin{tabular}{|c|c|c|c|c|}
\hline Scale Name & Scale Abbreviation & Scale No. & Raw Score with K* & T-score with $\mathrm{K}^{*}$ \\
\hline Lie & $\mathrm{L}$ & Validity & 4 & 52 \\
\hline Infrequency & $\mathrm{F}$ & Validity & 20 & 106 \\
\hline Defensive & $\mathrm{K}$ & Validity & 13 & 46 \\
\hline Hypochondrias & Hs & 1 & 23 & 71 \\
\hline Depression & $\mathrm{D}$ & 2 & 42 & 96 \\
\hline $\begin{array}{l}\text { Hysteria+ } \\
\text { (Conversion) }\end{array}$ & Hy & 3 & 39 & 89 \\
\hline $\begin{array}{l}\text { Psychopathy+ } \\
\text { (Rebelliousness) }\end{array}$ & $\mathrm{Pd}$ & 4 & 41 & 97 \\
\hline Masculinity-Feminity & Mf & 5 & 36 & 50 \\
\hline Paranoia & $\mathrm{Pa}$ & 6 & 26 & 107 \\
\hline $\begin{array}{l}\text { Psychasthenia }+ \\
\text { (Obsessive-compulsive) }\end{array}$ & $\mathrm{Pt}$ & 7 & 37 & 68 \\
\hline Schizophrenia & $\mathrm{Sc}$ & 8 & 43 & 76 \\
\hline Hypomania & $\mathrm{Ma}$ & 9 & 24 & 62 \\
\hline Social Introversion & $\mathrm{Si}$ & 0 & 46 & 70 \\
\hline
\end{tabular}

* $\mathrm{K}$ is added to five clinical scales (Hs, Pd, Pt, Sc, Ma)

+ Note new name in brackets

Table 2. Assessment Outcomes from MMPI-2 Supplemental Scales

\begin{tabular}{lccc}
\hline Scale name & Scale Abbreviation & Raw Score & T-score \\
\hline & & & \\
Anxiety & ANX & 21 & 84 \\
Fears & FRS & 8 & 53 \\
Family problems & FAM & 17 & $>99$ \\
Low Self-Esteem & LSE & 12 & 65 \\
Social Discomfort & SOD & 18 & 72 \\
Shyness & Si1 & 8 & 57 \\
Social Avoidance & Si2 & 8 & 74 \\
Alienation (self \& others) & Si3 & 12 & 69 \\
Post-Traumatic Stress Disorder & PK & 39 & 96 \\
Familial Discord & Pd1 & 9 & 92 \\
\hline
\end{tabular}


Table 3. Suggested Intervention Plan for $\mathrm{P}$

\begin{tabular}{|c|c|c|c|c|}
\hline & Type 1 & Type 2 & Type 3 & Type 4 \\
\hline \multirow[t]{7}{*}{ Problems } & Depression & Family problems & Social avoidance & Paranoia \\
\hline & Anxiety & Familial discord & Social discomfort & Psychopathy \\
\hline & Stress (PTSD) & & Alienation & Hysteria \\
\hline & Fears & & Shyness & Schizophrenia \\
\hline & & & Social introversion & Hypochondrias \\
\hline & & & Low self-esteem & Psycasthenia \\
\hline & & & & Hypomania \\
\hline \multirow[t]{6}{*}{ Therapies } & Cognitive-Behavioral & Family counseling & Systematic & Bibliotherapy \\
\hline & Therapy (CBT) & Rational Emotive & desensitization & Psychotherapy \\
\hline & Relaxation & Therapy (RET) & (SD) & Drug therapy \\
\hline & & & Social skills & $(\mathrm{DT})$ \\
\hline & & & training & \\
\hline & & & $(\mathrm{SST})$ & \\
\hline Sessions & Individual & Group & Individual & Individual \\
\hline \multirow[t]{4}{*}{ Helpers } & Multiteam & Psychologist & Psychologist & Psychiatrist \\
\hline & (psychologist, & Counsellor & Counsellor & Clinical \\
\hline & counsellor, & Social worker & (one) & psychologist \\
\hline & social worker) & (one) & & (one) \\
\hline
\end{tabular}

